\title{
Measurement, validity, and dimensionality of Jennifer Aaker's brand personality scale for a mobile telephone brand in a developing country
}

\author{
Peter N. Kiriri \\ United States International University - Africa, Kenya
}

\author{
Keywords \\ Aaker; Branding; Brand personality dimensions; Brand personality scale; Kenya; Scale validation
}

\begin{abstract}
Branding and brand personality have become major areas of interest for marketing strategists and academicians. This has, in turn, led to an interest in determining ways to judge brands' own personality and the implications for these in the market. In 1997, Jennifer Aaker developed a brand personality scale which identified five key brand dimensions. Her study was conducted in the U.S., and since then researchers have assessed the reliability, validity, and dimensionality of her scale in different parts of the world. There has however been a paucity of studies in Africa, including Kenya, that focus on validating Aaker's brand personality scale. This study was centered on assessing the reliability, validity, and dimensionality of the brand personality scale in Kenya, a developing country. In doing so, data was gathered from customers of Safaricom, a mobile phone service provider. The sample for this study was drawn from both undergraduate and graduate students at the United States International University - Africa. The data collection instrument was an adaptation of Aaker's brand personality scale, with 42 items. Altogether, 211 completed questionnaires were used in the final analysis. Cronbach's Alpha values of each construct confirmed that good reliability exists with the data. Principle component analysis was employed to determine the important factors of brand personality. As opposed to the 42 items in the Aaker scale, only 22 were found to satisfy requirements, and 20 items were therefore discarded. Seven dimensions were identified through the CFA, as opposed to the five by Aaker. A structural equation model was developed showing the relationships between the seven dimensions and brand personality, and all the seven were significant. Safaricom brand personality was identified as excitement by consumers after the regression path coefficient.
\end{abstract}

Corresponding author: Peter N. Kiriri

Email addresses for the corresponding author: pnkiriri@usiu.ac.ke

First submission received: $1^{\text {st }}$ April 2019

Revised submission received: $2^{\text {nd }}$ April 2019

Accepted: $9^{\text {th }}$ May 2019

\section{Introduction}

In the recent past, due to developments in globalization and information technology, competition in many sectors has intensified. This has resulted in the performance of many companies becoming affected, either positively or negatively, based on their response strategy to the market's dynamism. However, as more developments arise in the marketing field, competition is shifting increasingly from physical products to the consumer's perception of organizations' brands. The organization is developing strategies to influence the perception of consumers to gain levels of association and loyalty. As a result, the building of brands has become particularly important for organizations and marketing strategists.

Brand strategies are important in creating brand differentiation to combat competition in the current dynamic and turbulent marketplace. Branding strategy can help marketers achieve a sustainable competitive advantage and thereby influence a firm's performance significantly. According to Roosta and Madani (2011), due to the high cost of creating new brands, organizations invest on their current brands to maximize their profit by increasing the brand value and reputation in today's competitive environment. When consumers associate themselves with a brand having positive attributes, this influences the relationship between the brand and the consumer. As a result, consumers exploit brands to construct and maintain their identity through the brand traits that help them propagate and achieve their desires.

In addressing brand issues, marketers must establish the distinctiveness of a brand through brand personality (Thomas \& Sekar, 2008). By attaching personalities to brands, they differentiate brand identity, 
which can make brands more desirable to the consumer, as the brand acquires an identity and personality line (Bouhlel et al., 2009; Thomas \& Sekar, 2008). Brand personality studies have helped marketers to identify humanlike traits in the products and use the same to align their brands with the desired markets. It is within the scope of understanding the brand personality of mobile phone services that this study was undertaken in Kenya.

The mobile phone service sector in Kenya has grown by leaps and bounds over the past 20 years following liberalization of the sector. The different players in the sector have implemented various marketing strategies and tactics to ensure growth and consolidate their market presence. Brand building has been part of the efforts to build a loyal market base.

According to the Communications Authority of Kenya (CAK), mobile phone users in the country stood at 46.6 million as at 30 September 2018. Mobile penetration (the total number of active SIM cards calculated as a percentage of total population in the country) was at 100.1 per cent, attributed to the fact that most users owned more than one SIM card either from the same or different service providers. According to the Kenya Integrated Household Budget Survey (KIHBS) for 2018, at least 30 per cent of mobile users in Kenya owned more than one SIM card, which translated to an average of 1.3 SIM cards per subscriber (Kenya National Bureau of Statistics [KNBS], 2018). In terms of mobile money, by the end of the first quarter of the Financial Year 2018/19, the number of active mobile money transfer agents and subscriptions stood at 218,495 and 29.7 million, respectively. This implied that 64 out of 100 inhabitants had access to and used mobile money transfer services during the period. In Kenya, by 2018, there were three main mobile phone operators - Safaricom Plc, Airtel Kenya, and Telkom Kenya Ltd. Safaricom has been the dominant market player with about 64.2 per cent market share followed by Airtel and Telkom with 22.3 per cent and 9 per cent, respectively, as at September 2018 (CAK, 2018).

Safaricom is one of the most profitable companies in East and Central Africa. The company offers mobile telephony, mobile money transfer, consumer electronics, e-commerce, cloud computing, data, music streaming, and fibre optic services. Safaricom was formed as a private limited liability company (LLC) in 1997 and became a publicly traded company in 2002. The original company was 60 per cent owned by the government of Kenya. In 2000, Vodafone acquired a 40 per cent stake in the company through Vodafone Kenya Ltd, as well as management responsibility for the company. In 2008, the government sold a 25 per cent stake to the public through the Nairobi Securities Exchange.

Mobile telephony has become part of the life of citizens in the country. The use of mobile services has facilitated various economic sectors through communication, data and money transfer. Safaricom, being the market leader, has been a major focus of the regulator in terms of service provision and quality. Its 64.2 per cent market stake means that the majority of Kenyans subscribe to its services. As a result, it would be of interest to know the perception of Kenyans about Safaricom as a brand-and more specifically the human personality traits it possesses. This study endeavoured to determine Safaricom's brand personality.

\section{Literature review \\ Brand personality}

The topic of brand personality has received a lot of attention in the past two decades. It has become widely accepted as an effective way to capture the perception of customers, thereby influencing their choices (Cialdini \& Trost, 1998; Aaker, 2012). Much of the discussion was elicited after the seminar research of Jennifer Aaker in 1997. Brand personality has been defined as the human characteristics, or traits, that can be attributed to a brand (Aaker, 1997; Azoulay \& Kapferer, 2003). The term "brand personality" refers to a set of human characteristics associated with a brand.

According to Aaker (1997), brands have similar traits as individuals, and people would tend to buy those brands with which they share some characteristics. In associating with brands that have similar traits like them, consumers become loyal to those brands since they share "something" in common. Aaker proposed five dimensions to measure the personality of a brand-Sincerity, Excitement, Competence, Sophistication, and Ruggedness. She developed five-point scales to measure these five traits, and initially utilized 114 traits, later reducing them to 42.

A strong and positive brand personality can be the basis of product differentiation. Potential benefits include an increase in consumer preferences, usage, trust and loyalty (Freling, 2005). A distinctive 
brand personality can help to create a set of unique and favourable associations in consumer memory, and thus build and enhance brand equity (Johnson, Soutar \& Sweeney, 2000). This is because brand personality tends to serve a symbolic or self-expressive function (Keller, 1993). Marketers have long associated their brands with various traits-for instance, cool, trendy, soft, and strong-making consumers want to associate with brands having traits they want to be linked with. As such, consumers desire to be imbued with a brand having the personality trait they prefer (Aaker, 1997).

The personality of a brand enables a consumer to express him or herself as an ideal self or in specific dimensions of the self ((Belk, 1988; Kleine, Kleine \& Kernan, 1992) through the use of a brand. It allows marketers the ability to market brands across different cultures (Plummer, 1985). According to Malhotra (1988), the greater the congruence between the human characteristics that consistently and distinctively describe an individual's actual or ideal self and those that describe a brand, the greater the preference of the brand.

\section{Brand personality dimensions}

Based on Aaker's research, five brand personality dimensions were developed. The five factors were as a result of an analytical process that reduced the 114 initial traits to 42 , which were composed into the five dimensions. Because the research was conducted in the U.S., Aaker recommended that further research be conducted in different cultural settings to find out the dimensionality and validity of the brand personality scale (BPS) developed. As a result, several studies have been conducted to validate Aaker's scale. Some researchers have identified brand personality to be a uni-dimensional construct, while others have identified different dimensions. The number of items under each dimension has also differed in varying contexts of the study - such as cultural and demographic contexts. As a result, researchers have focused on developing country-specific brand personality scales. Even where a study found out fivefactor brand personality dimensions, the total number of items in the personality scale differed from study to study.

Several studies have examined the dimensionality of brand personality in different settings and across cultures. Although some studies on the application and validation of Aaker's (1997) brand personality scale reveal the emergence of culturally specific dimensions, the brand personality scale remains the most stable, reliable and comprehensive measure to gauge brand/product personality. However, for most previous studies exploring the dimensions of brand personality using the BPS, a set of three relatively consistent dimensions usually emerges - namely, sincerity, excitement, and sophistication (Ekinci \& Hosany, 2006).

Different studies have found different dimensions. Geuens, Weijters and De Wulf (2007) found five factors, which consisted of 12 items: Activity, responsibility, aggressiveness, simplicity, and emotionality. Thomas and Sekar (2008) identified 13 dimensions of brand personality with about 10 items of Aaker's Brand Personality Scale not applicable in the Indian situation. In the tourism sector, tourists ascribed personality characteristics to destinations, aligning destination personality to the three dimensions of sincerity, excitement, and conviviality (Ekinci \& Hosany, 2006). Similarly, Murhpy (2016) found three dimensions of excitement, sincerity, and sophistication in destination tourism. In Malaysia, Mohtar et al. (2013) found 12 brand personality dimensions in their study. Tong, Su and Xu (2018) revealed that American consumers perceived six distinct personality dimensions and 37 personality traits in luxury fashion brands. In researching television news, Chan-Olmsted and Cha (2008) found three dimensions, contrary to a study on news media by Kim, Tae and Martin (2010) who found five brand personality dimensions. A different study on print media in France by Valette-Florence and de Barnier (2013) found eight dimensions. Supphellen and Grønhaug's (2003) study of Russia found five dimensions, which they identified as successful and contemporary, sincerity, excitement, sophistication, and ruggedness.

The brand personality dimensions have been applied to various settings across different cultures to gauge consumers' symbolic consumption and their effects on behaviour (Aaker, Benet-Martinez \& Garolera, 2001). As can be seen, the number of dimensions by researchers ranges from 1 to 12 based on the context-specific issues under investigation. Table 1 provides a summary of various studies, country of research and the number of dimensions. 


\begin{tabular}{llc}
\hline Author (s) & Country & No. of dimensions \\
\hline Aaker (1997) & US & 5 \\
Aaker (1997) & Japan & 5 \\
Aaker, Benet- Martinez, and Garolera (2001) & Japan & 5 \\
Bosnjak, Bochmann, and Hufschmidt (2007) & Spain & 4 \\
Caprara, Barbaranelli and Guido (2001) & Germany & 4 \\
d'Astous and Lévesque (2003) & Italy & 5 \\
Davies, Chun, Vinhas da Silva, and Roper (2004) & Canada & 5 \\
Ferrandi, Valette-Florence, and Fine-Falcy (2000) & US & 5 \\
Helgeson and Supphellen (2004) & France & 2 \\
Hosany, Ekinci, and Uysal (2006) & Sweden & 3 \\
Kim, Han, and Park (2001) & Sweden & 5 \\
Milas and Mlačić (2007) & Korea & 5 \\
Smit, van den Berge, and Franzen (2002) & Croatia & 5 \\
Sung and Tinkham (2005) & Netherlands & 8 \\
Venable, Rose, Bush, and Gilbert (2005) & USA & 8 \\
\hline
\end{tabular}

Table 1: Number of Dimensions by and Countries

Source: Geuens, Weijters \& De Wulf (2007)

Brand personality scale

In the measurement of brand personality scale, Aaker's scale developed in 1997 has been widely used. Her seminal work provided an impetus to brand personality measurement, which was previously done on scales that had not gone through the process of development and testing for reliability and both convergent and discriminant validity. Some researchers have either adopted or modified Aaker's brand personality scale, while others have criticized the scale and gone ahead to propose a new scale altogether. Aaker's (1997) work has been considered as widely applicable, widely cited, and arguably the most influential research on brand personality scale (Cui et al., 2008; Kaplan et al., 2010). According to Aaker (1997), the framework of the five brand personality dimensions are reliable, valid, and generalizable, and appear to best explain the way American consumers perceived brands across symbolic and utilitarian product and service categories.

While discussion has revolved around the adaptability of the study to various contexts and its ability to achieve construct validity, there has been a consensus that Aaker's scale-with contextual modifications - is still the most popular scale. It is widely accepted by researchers, with most brand personality measurements based on it. The scale has been demonstrated to be a reliable, valid, and generalizable scale for assessing brand personality in some studies. The scale has also been identified as a useful tool for diagnosing brand personality to improve the alignment between consumer perception and desired symbology (Siguaw et al., 1999; Deane et al., 2003).

The scale has also been used in different industries and cultural contexts (Aaker et al., 2001; Siguaw et al., 1999). For example, adopting Aaker's framework, Ekinci and Hosany (2006) revealed that Aaker's methodology could be applied to tourism destinations. Kaplan et al. (2010) examined the applicability of Aaker's brand personality concept for city brands and concluded that brand personality dimensions are applicable to place brands. Kim, Baek and Martin (2010) studied dimensions of news media brand personality, guided by Aaker's brand personality study. Tong and Su (2014) revealed that Aaker's methodology could be applied to sportswear brands. Other researchers have used the scale on consumer goods (Kim, 2000; Aaker, Benet-Martinez \& Garolera, 2001; Kim, Han \& Park, 2001); restaurant settings (Siguaw, Mattila \& Austin, 1999); and web sites (Muller \& Chandon, 2003).

Some research has indicated that Aaker's (1997) brand personality scale is not generalizable. In some cases, the scale has also been found not replicable across different scenarios, as there were personality attributes different from the five identified (Aaker et al., 2001; Austin et al., 2003; Azoulay \& Kapferer, 2003; Caprara et al., 2001; Geuens et al., 2009). A study by Geuens et al. (2009), however, argued that the brand personality scale could be used in cross-cultural studies. Even with all these issues, Aaker's model still yields good results (Terason, 2012; Xu et al., 2016; Ratnesh \& Kansal, 2017; Bouhlel et al., 2009). 


\section{Problem statement}

Aaker's (1997) brand personality scale has not only been replicated and extended across cultures, but also applied to many countries. However, there is a paucity of research in Africa, including Kenya. There is also minimal research on the dimensionality and reliability of the scale in the telecommunication sector, and specifically on mobile telephone services. Accordingly, this study focused on exploring the applicability of Aaker's Brand Personality Scale on a mobile phone services company. It also aimed at measuring and validating Aaker's Brand Personality Scale.

\section{Research objectives}

- The general objective of this study was to test the psychometric properties of Aaker's Brand Personality Scale. Specifically, this study was focused on addressing the following objectives:

- To identify the psychometric properties of the brand personality scale applicable to mobile phone services in Kenya.

- To determine the dimensionality of mobile phone services brand personality.

- To determine the brand personality of Safaricom.

\section{Methodology}

The research design for this study was both descriptive and explanatory. The target population of this study was both graduate and undergraduate students at a university in Kenya. From the targeted students, 211 completed and returned the questionnaires. For factor analysis and measurement scale testing, a sample size of 200 is deemed adequate. To participate, the students were required to have interacted with the products of Safaricom, namely voice and money transfer services. This was to ensure that responses were received from students who had experience and therefore would be able to relate some personality traits to the services in question. The data collection instrument was an adaptation of the original brand personality scale developed by Aaker (1997) with 42 items. The choice of the original scale was because the current study intended to test the reliability, dimensionality, and validity of the scale in a different market context from the original. The tool was subjected to pre-test, and while none of the scale items was omitted, some item wordings were changed to reflect appropriate meaning and relevance in the Kenyan situation.

Factor analysis was used to explore the data and its structure. To determine the number of factors to extract, principal component analysis was used as the extraction method, while the rotation method was an oblique rotation, specifically Promax (Tabachnick \& Fiddell, 2007; Thurstone, 1947), with Kaiser Normalization. After the factor analysis, confirmatory factor analysis (CFA) was performed to test the fit of the model used. The scale's internal consistency was tested by using reliability analysis with Cronbach's alpha (a minimum of 0.7 was deemed acceptable), while the construct validity was tested by employing confirmatory factor analysis (CFA), which was performed using the structural equation modelling (SEM).

Sample demographic profile

From the responses, 46 per cent of the respondents were males while 54 per cent were females. In terms of the distribution of the respondents' age, 6 per cent were below 20 years, 77 per cent between 20 and 30 years; 14 per cent between 31 and 40 years; and, 3 per cent over 40 years. Other sample demographic profiles are as presented in the table below.

\begin{tabular}{lll}
\hline Demographic data & Categories & Percent \\
\hline Gender & Male & 46 \\
& Female & 54 \\
Age Category & Below 20 Years & 6 \\
& 20 - 30 Years & 77 \\
& $31-40$ Years & 14 \\
Student Status & Over 40 Years & 3 \\
& Graduate & 28 \\
& Undergraduate & 72 \\
\hline
\end{tabular}

Table 2: Sample Demographic Profile 


\section{Data analysis and results \\ Reliability}

The scale's internal consistency was tested by using reliability analysis with Cronbach's alpha. The Cronbach alpha for the variables used to construct the scales was 0.907. A Cronbach alpha of 0.70 is considered acceptable (Nunnally, 1978; Hatcher, 1994; Field, 2009). The adequacy and suitability of the sample for factor analysis were checked using the Kaiser-Meyer-Olkin (KMO) measure. In this study, KMO test was 0.799 , fulfilling the requirements for adequacy of data for factor analysis as recommended by Field (2009). The Bartlett's test of sphericity was also used to test if the sample is from a population with equal variances (homoscedasticity or homogeneity of variances). In this study, data were suitable for performing EFA as indicated by Bartlett's test of sphericity, yielding significance $(p<0.001$, approximate Chi-square of 1680.26, with 231 degrees of freedom).

Factor analysis

To examine the dimensionality of the scale construct, exploratory factor analysis was undertaken. To determine the number of factors to extract, principal component analysis was used as the extraction method, while the rotation method was an oblique rotation, specifically Promax (Tabachnick \& Fiddell, 2007) with Kaiser Normalization as recommended.

Seven factors emerged after satisfying the two required tests, including the Kaiser criterion (eigenvalues greater than 1) and a scree plot. These factors accounted for 66.6 per cent of the total variance. Field (2009) suggests that the minimum In identifying the items loading on each component, out of the 42 items in the questionnaire derived from the Aaker (1997), 20 items were found not to satisfy the requirements for inclusion as their factor loadings were below the recommended 0.5 and thus were omitted, leaving 22 items for further analysis.

Based on the items in each component, some suggested themes arise. Some of the themes were in line with Aaker's original scale. However, unlike where she had five factors, seven factors were identified in the current study. The factors were named as sincerity, competence, excitement, assertiveness, ruggedness, sophistication, and gentleness. The table below provides the various items, components, and their factor loadings.

\begin{tabular}{|c|c|c|c|c|c|c|c|}
\hline \multirow{2}{*}{ Trait } & \multirow[b]{2}{*}{ Sincerity } & \multirow[b]{2}{*}{ Competencet } & \multirow[b]{2}{*}{ Excitement } & \multicolumn{2}{|c|}{ Component } & \multirow[b]{2}{*}{ Sophistication } & \multirow[b]{2}{*}{ Gentleness } \\
\hline & & & & Assertiveness & Ruggedness & & \\
\hline Sincere & .936 & & & & & & \\
\hline Real & .902 & & & & & & \\
\hline Honest & .888 & & & & & & \\
\hline Wholesome & .592 & & & & & & \\
\hline Secure & & .938 & & & & & \\
\hline Intelligent & & 690 & & & & & \\
\hline Hardworking & & 685 & & & & & \\
\hline Technical & & 655 & & & & & \\
\hline Spirited & & & 961 & & & & \\
\hline Exciting & & & .693 & & & & \\
\hline Imaginative & & & 632 & & & & \\
\hline Cheerful & & & 612 & & & & \\
\hline Confident & & & & .834 & & & \\
\hline Leader & & & & .824 & & & \\
\hline Successful & & & & .563 & & & \\
\hline Upper-class & & & & & .863 & & \\
\hline Glamorous & & & & & .811 & & \\
\hline Tough & & & & & & .825 & \\
\hline Rugged & & & & & & .755 & \\
\hline Masculine & & & & & & 631 & \\
\hline Feminine & & & & & & & .873 \\
\hline Smooth & & & & & & & .559 \\
\hline
\end{tabular}

Table 3: Factor Analysis Component Loadings 


\section{Component relevance}

The components derived through factor analysis were tested to derive the most relevant for the Kenyan environment (Table 4). The descriptive analysis indicated a mean score for Brand Personality of 3.23. The highest mean score for the factors was posted by assertiveness (3.68), followed by sincerity (3.68), then competence (3.66) and lastly excitement (3.41). Other descriptive statistics were used, including standard deviation, skewness, and kurtosis for the latent variable and factors. From the analysis, the data was found to achieve normality and therefore appropriate for further analysis.

\begin{tabular}{llllc}
\hline Component/Determinant & Mean & Std. Deviation & Skewness & Kurtosis \\
\hline Brand Personality & 3.2290 & .54805 & -.430 & -.080 \\
Gentle & 1.5241 & .40847 & -.046 & -.411 \\
Sophistication & 2.1983 & .68888 & -.155 & -.668 \\
Ruggedness & 2.9546 & .96431 & -.151 & -.714 \\
Assertive & 3.6810 & .61852 & -.724 & -.071 \\
Excitement & 3.4073 & .67207 & -.662 & .246 \\
Competent & 3.6643 & .74609 & -.587 & .132 \\
Sincerity & 3.6793 & 1.10752 & -.312 & -.719 \\
\hline
\end{tabular}

Table 4: Component Relevancy

Confirmatory Factor Analysis (CFA) - testing of the measurement model

After the factor analysis, confirmatory factor analysis (CFA) was performed to test the fit of the scales suggested to the Kenyan situation. The scales' construct validity was tested by employing CFA. According to Byrne (2009), CFA can be used to determine whether the sample data is compatible with the hypothesized model of the study. Maximum likelihood estimation procedure was selected as the best method to conduct CFA as normality is assured in the data set. Several fit indices were used to test the model fit. The chi-square, degrees of freedom, the root mean square error of approximation (RMSEA), and comparative fit index (CFI) were determined as recommended by Hair et al. (2010).

In assessing goodness of fit, the ratio of chi-square to the degree of freedom $\left(\chi^{2} / \mathrm{df}\right)$ is used. According to Hooper et al. (2008), $x 2$ /df should be less than 3 to indicate an acceptable fit. In this study, $x^{2} / \mathrm{df}$ was 1.873, indicating an acceptable fit for this model as it was less than the 3 recommended. For the RMSEA, MacCallum, Browne, and Sugawara (1996) suggest that an RMSEA value of between 0.00 and 0.05 indicates a close model fit, a value of between 0.05 and 0.08 a reasonable fit, and a value of more than 0.08 a poor model fit. In this study, a RMSEA of 0.064 was achieved, indicating a reasonable model fit. The CFI values should range between 0.0 and 1.0, with values closer to 1.0 indicating a good fit (Hooper et al., 2008). The CFI of this study was 0.892 , indicating an acceptable model fit as provided in the table below.

\begin{tabular}{llll}
\hline Measurement & Index & Threshold & Interpretation \\
\hline Chi- square $\left(\chi^{2}\right)$ & 352.214 & - & - \\
Degree of freedom & 188 & - & - \\
X2/df & 1.873 & Between 1 and & Excellent \\
& & 3 & Acceptable \\
RMSEA & 0.064 & $<0.06$ & Acceptable \\
CFI & 0.892 & $>0.95$ & Excellent \\
SRMR & 0.069 & $<0.08$ & Acceptable \\
PClose & 0.013 & $>0.05$ & .
\end{tabular}

Table 5: Goodness of Fit Indices

Assessing the validity of scale measures

Confirmatory Factor Analysis (CFA) is used to test the discriminant and convergent validity of factors. The CFA analysis was undertaken using SPSS AMOS software. Campbell and Fiske (1959) proposed two aspects to assess the construct validity of a test: Convergent validity, which is the degree of confidence that a trait is well measured by its indicators; and discriminant validity, which is the degree to which measures of different traits are unrelated. In structural equation modeling, CFA is usually used to assess construct validity (Jöreskog, 1969). 


\section{Convergent validity}

According to Fornell and Larcker (1981), the convergent validity of a measurement model can be assessed by the Average Variance Extracted (AVE) and Composite Reliability (CR). AVE values above 0.7 are considered good, even though 0.5 is also acceptable. Based on the test of the scale, convergent validity was achieved as all the constructs posted an AVE greater than 0.5, which is acceptable (See table below). On the other hand, all the factors except assertiveness recorded a CR of above 0.7. These results indicate that the scale had achieved convergent validity.

\begin{tabular}{llll}
\hline Factors & CR & AVE & MSV \\
\hline Sincerity & 0.883 & 0.658 & 0.263 \\
CompetentCompetence & 0.779 & 0.672 & 0.365 \\
Excitement & 0.745 & 0.529 & 0.365 \\
Assertiveness & 0.678 & 0.514 & 0.333 \\
Ruggedness & 0.702 & 0.567 & 0.048 \\
Sophistication & 0.764 & 0.632 & 0.150 \\
Gentleness & 0.700 & 0.587 & 0.169 \\
\hline
\end{tabular}

Table 6: Convergent and Discriminant Validity Measures

\section{Discriminant validity}

Discriminant validity refers to the extent to which factors are distinct and uncorrelated. According to Fornell and Larcker (1981), discriminant validity can be assessed by comparing the amount of the variance captured by the construct (AVE) and the shared variance with other constructs (maximum shared variance - MSV). According to Hair et al. (2010), discriminant validity is established where MSV is lower than AVE for all constructs. In testing the scale, and as indicated in the table above, in all the seven factors MSV was lower than AVE and thus achieving the required threshold for discriminant validity. On the other hand, as indicated in Table 6 and Figure 1 below, all the seven factors were significantly correlated at $\mathrm{p}<0.05$ level.

\section{Determinants Correlation Matrix}

From the analysis (see Table 7 and Figure 1), the correlation between sincerity and competence, excitement and assertiveness; competence and excitement and assertiveness; and excitement and assertiveness, were significant at $\mathrm{p}<0.001$ level. The other correlations were significant either at $\mathrm{p}<0.050$ or $p<0.010$ levels. The ruggedness dimension, when correlated with the other factors, was not significant.

\begin{tabular}{llllllll}
\hline Determinant & Sincerity & Competence & Excitement & Assertiveness & Ruggedness & Sophistication & Gentleness \\
\hline Sincerity & $\mathbf{1}$ & & & & & & \\
Competence & $0.409^{* * *}$ & $\mathbf{1}$ & & & & & \\
Excitement & $0.513^{* * *}$ & $0.604^{* * *}$ & $\mathbf{1}$ & & & \\
Assertiveness & $0.404^{* * *}$ & $0.577^{* * *}$ & $0.531^{* * *}$ & $\mathbf{1}$ & & \\
Ruggedness & 0.143 & $0.158 \dagger$ & 0.113 & 0.083 & $\mathbf{1}$ & & \\
Sophistication & $0.185^{*}$ & $0.386^{* *}$ & $0.388^{* *}$ & $0.281^{* *}$ & $0.219^{*}$ & $\mathbf{1}$ & \\
Gentleness & $0.356^{* *}$ & $0.339^{*}$ & $0.411^{* *}$ & $0.302^{*}$ & 0.19 & $0.360^{*}$ & $\mathbf{1}$ \\
\hline
\end{tabular}

Table 7: Determinants Correlation Matrix

Significance of Correlations: $\dagger \mathrm{p}<0.100 ; * \mathrm{p}<0.050 ; * * \mathrm{p}<0.010 ; * * * \mathrm{p}<0.001$ 


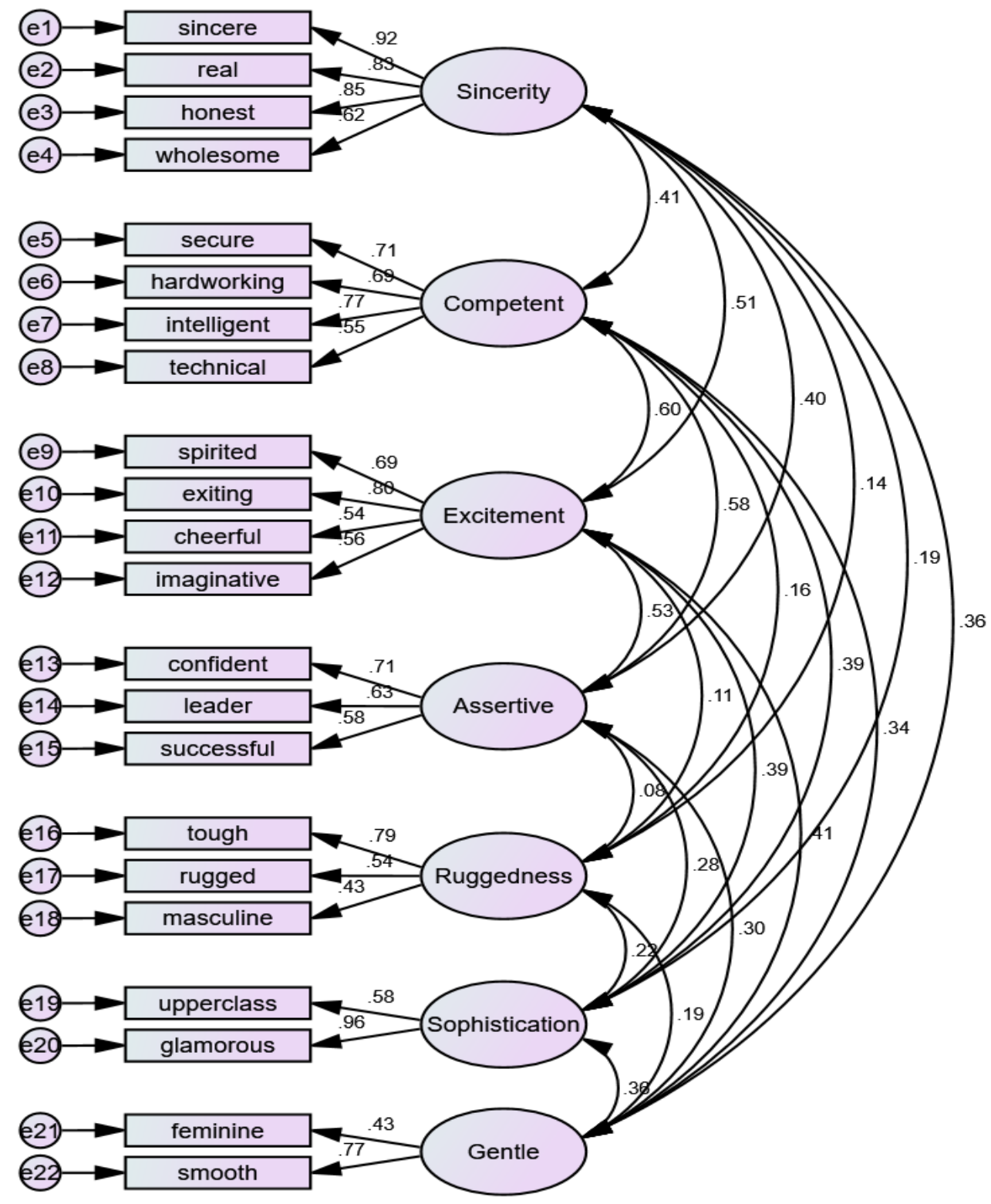

Figure 1: First Order Brand Personality Dimensions CFA Path Analysis

The second order CFA and path analysis

The second order CFA is employed to confirm that the theorized construct in a study loads into a certain number of underlying sub-constructs or components. Second-order models are most typically applicable in research contexts in which measurement instruments assess several related constructs, each of which is measured by multiple items. The second-order model represents the hypothesis that these seemingly distinct but related constructs can be accounted for by one or more common underlying higher order constructs. In order to determine the higher order construct, a second order CFA was computed. 


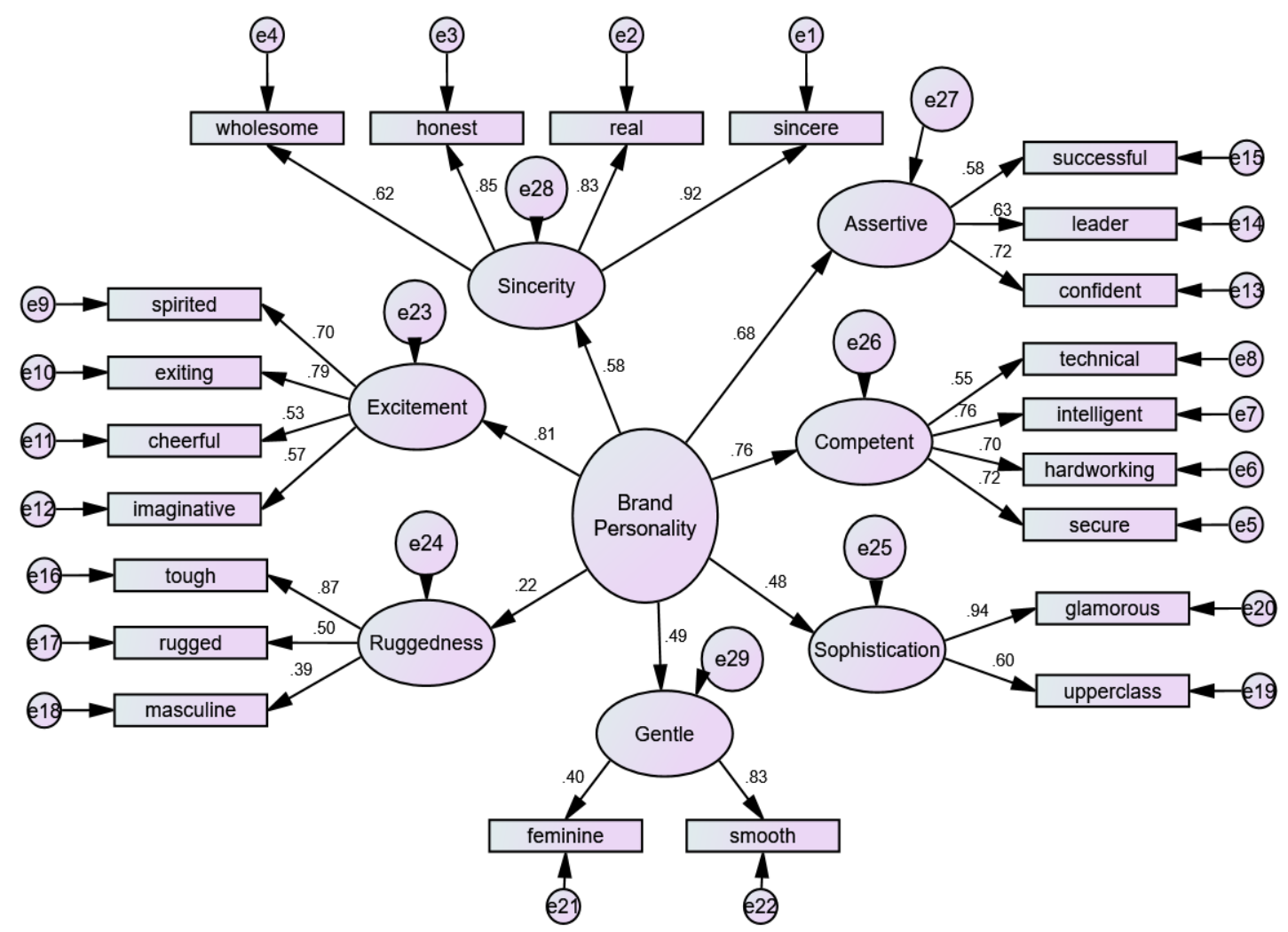

Figure 2: Second Order Brand Personality Dimensions CFA Path Analysis

Model Fit Assessment with Path Analysis (Causal Modelling)

In order to test the fitness of the model, various fit indices were used. The chi-square, degrees of freedom, the root mean square error of approximation (RMSEA), standardized root mean square residual (SRMR), comparative fit index (CFI) and p of Close Fit (PCLOSE) are measures recommended to be used (Hair et al., 2010). In this study, all the model fit indices were attained as provided in Table 8 below.

\begin{tabular}{llll}
\hline Measurement & Index & Threshold & Interpretation \\
\hline Chi- square $\left(\mathrm{X}^{2}\right)$ & 366.179 & - & - \\
Degree of freedom & 202 & - & - \\
X2/df & 1.813 & Between 1 and 3 & Excellent \\
RMSEA & 0.062 & $<0.06$ & Acceptable \\
SRMR & 0.074 & $<0.08$ & Excellent \\
CFI & 0.892 & $>0.95$ & Acceptable \\
PClose & 0.026 & $>0.05$ & Acceptable \\
\hline
\end{tabular}

Table 8: Goodness of Fit Indices - CFA Second Order

Path Analysis

Path analysis using Structural Equation Modeling (SEM) was also undertaken to test the model and relationships among measured variables. The path analysis, sometimes referred to as causal modelling, tests a specific pattern of relationships among variables, in which some are assumed to be the cause of the other(s). It examines the relationships between a dependent variable and two or more independent variables. By using this method, one can estimate both the magnitude and significance of causal connections between variables.

From the path analysis model estimates, all item loadings were significant at $p<0.05$. The critical ratios (CR) for each path exceeded the threshold values required. When the critical ratio (CR) is $>1.96$ for a regression weight, that path is significant at the .05 level. Based on the regression coefficients, there is a 
positive significant relationship between all the seven dimensions and brand personality. The results of SEM analysis are presented in the table below.

\begin{tabular}{llllllll}
\hline Regression path & & & B & Beta & S.E. & C.R. & P \\
\hline Sincerity & $<---$ & Brand Personality & 1.363 & 0.580 & 0.256 & 5.333 & $* * *$ \\
Assertive & $<---$ & Brand Personality & 0.785 & 0.680 & 0.143 & 5.500 & $* * *$ \\
Competent & $<---$ & Brand Personality & 1.273 & 0.759 & 0.232 & 5.500 & $* * *$ \\
Sophistication & $<--$ & Brand Personality & 0.711 & 0.480 & 0.214 & 3.316 & $* * *$ \\
Gentle & $<--$ & Brand Personality & 0.483 & 0.494 & 0.202 & 2.389 & 0.017 \\
Ruggedness & $<---$ & Brand Personality & 0.484 & 0.218 & 0.207 & 2.343 & 0.019 \\
Excitement & $<---$ & Brand Personality & 1.226 & 0.807 & 0.222 & 5.510 & $* * *$ \\
\hline
\end{tabular}

Table 9: The regression path coefficient and its significance

\section{Conclusions and implications}

This study was driven by three broad objectives. The first was to evaluate the psychometric properties of Aaker (1997) brand personality scale in order to determine its applicability in Kenya. The second was to determine the dimensionality of mobile phone services brand personality. The third was to determine the brand personality of Safaricom Plc.

\section{Conclusions}

On the first objective, in testing the psychometric properties of the brand personality scale, it was found that out of the 42 items in the Aaker (1997) scale, only 22 were applicable to the Kenyan mobile phone sector as 20 items were found not reliable. The difference could be attributed to the issues of cultural and contextual differences. The Aaker (1997) scale was developed in the U.S., which has different cultural orientations from the Kenyan situation. It was also developed using many products (goods), while this study focused on a service institution. Several other studies including those conducted in different geographical areas by Aaker have found differing scale items. In their study of Japanese and Spanish consumers, Aaker, Benet-Martinez and Garolera (2001) found scales with 36 and 33 items for the two countries, respectively. Bosnjak, Bochmann and Hufschmidt (2007) in their study in Germany ended up with a scale of 20 items. Tong, Su and Xu (2018) identified a scale with 37 items in their study on luxury fashion products in the U.S. In India, Thomas and Sekar (2008) identified 32 items in their final list. Many researchers have argued that due to the differences in the respondents' demographic variables, product perceptions, and orientation, even consumers in the same geographical and cultural contexts can exhibit varying brand associative traits.

In terms of the dimensionality of the brand personality among Kenyan mobile phone users, seven dimensions were identified, in contrast to five by Aaker (1997). Again, due to emic and etic issues, as well as contextual differences, different dimensions have been found in different studies globally. Geuens et al. (2007) found five factors in their study. Thomas and Sekar (2008) identified 13 dimensions of brand personality in the Indian situation. Ekinci and Hosany (2006) conducted a study in the tourism sector and found three dimensions. Similarly, Murhpy (2016) found three dimensions of destination tourism. In Malyasia, Mohtar et al. (2013) found 12 brand personality dimensions in their study. Tong, Su and Xu (2018) revealed six distinct personality dimensions in U.S. luxury fashion brands. Baek, Kim and Martin (2010) found three dimensions in the media industry. Supphellen and Grønhaug's (2003) had five dimensions in a study in Russia. Further analysis of various studies in different countries and the number of dimensions is provided in Table 1.

The brand personality of Safaricom mobile service, from the analysis, was identified based on regression tests and significance levels. Most respondents felt the brand personality was excitement. Safaricom mobile services were therefore seen as spirited, exciting, cheerful, and imaginative. On the contrary, Safaricom was not perceived as being a rugged, sophisticated, and gentle brand.

The findings from this study can inform both practice and policy. They also contribute to the body of knowledge, especially about the usage of Aaker (1997) brand personality scale in a developing country, 
addressing a service sector. In terms of practice, marketing strategists will have a better understanding of the Kenyan consumer based on the dimensions of brand personality that were identified. Regarding knowledge, this study contributes to the knowledge gap and challenges as suggested by other researchers with respect to the applicability of a tool developed in a country with a different level of development and culture. Douglas and Nijssen (2003) recommended that extreme caution should be taken when using scales developed in one country or cultural context in other environments, especially in situations where the construct being measured is likely to be culturally embedded or related to macroeconomic country characteristics.

\section{Limitations and implications for future research}

This study had several limitations. The study's geographical scope was Nairobi, focusing on students in one university. The views of such a specific group may not represent the general populace. As such, the geographical and target population scope limits the generalizability of the findings. It is recommended that a broader study targeted at representative respondents be undertaken in the future. The study also focused on one service product. It would be important for future research to study different service products, including financial and non-financial services, to have a scale that can be applicable across the board.

Notwithstanding the above limitations, the study invariably contributes to knowledge in an underresearched area in Africa. Other researchers could focus on undertaking such a study focusing on different population and geographical scopes for comparison, as well as using different products. Research should also be conducted in other eastern African countries. This would allow a better comparative analysis with those in Western and Southern Africa.

\section{References}

Aaker, J., Benet-Martinez, V. and Garolera, J. (2001). Consumption Symbols as Carriers of Culture: A Study of Japanese and Spanish Brand Personality Constructs. Journal of Personality and Social Psychology, 81(3), pp.492508.

Aaker, D. (2012). Building strong brands. Simon and Schuster.

Aaker, J. (1997). Dimensions of brand personality. Journal of Marketing Research, 34(3), pp.347-356.

Azoulay, A. and Jean-Noel, K. (2003). Do Brand Personality Scales really Measure Brand Personality? Journal of Brand Management, 11(2), pp.143-155.

Austin, J., Judy, A., Siguaw, J. and Mattila, S. (2003). A Re-examination of the Generalizability of the Aaker Brand Personality Measurement Framework. Journal of Strategic Marketing, 11(6), pp.77-92.

Baek, T., Kim, J. and Martin, H. (2010). Dimensions of News Media Brand Personality. Journalism and Mass Communication Quarterly, 87(1), pp.119-136.

Belk, R. (1988). Possessions and the extended self. Journal of Consumer Research, 15, pp.139-168.

Bouhlel, O., Mzoughi, N., Hadiji, D. and Slimane, I. (2009). Brand Personality and Mobile Marketing: An Empirical Investigation. World Academy of Science, Engineering and Technology.

Caprara, G., Claudio, B. and Gianluigi, G. (2001). Brand Personality: How to Make the Metaphor Fit? Journal of Economic Psychology, 22, pp.377-395.

Chan-Olmsted, S. and Cha, J. (2008): Exploring the Antecedents and Effects of Brand Images for Television News: An Application of Brand Personality Construct in a Multichannel News Environment. The International Journal on Media Management, 10, pp.32-45.

Campbell, T., and Fiske, W. (1959). Convergent and Discriminant Validation by the Multitrait-Multimethod Matrix. Psychology Bulletin, 56, pp.81-105

Cialdini, R. and Trost, M. (1998). Social influence: Social Norms, Conformity, and Compliance. The Handbook of Social Psychology, 2, pp.151-192.

Communications Authority of Kenya (CAK). (2018). Sector Statistics Report Q1 2018-2019. Nairobi: CAK.

Cui, A., Albanese, P., Jewell, R. and Hu, M. (2008). Profiling the Brand Personality of Specific Brands. Advances in Consumer Research, 35, pp.534-541.

Douglas, S. and Nijssen, E. (2003). On the Use of "Borrowed" Scales in Cross-National Research: A Cautionary Note. International Marketing Review, 20(6), pp.621-642.

Ekinci, Y. and Hosany, S. (2006). Destination Personality: An Application of Brand Personality to Tourism Destination. Journal of Travel Research, 45(2), pp.127-139.

Field, A. (2009). Discovering statistics using SPSS. 3rd ed. London: Sage. 
Freling, T., and Forbes, L. (2005). An Examination of Brand Personality through Methodological Triangulation. Journal of Brand Management, 13, pp.148-162.

Freling, T., Crosno, J. and Henard, D. (2011). Brand Personality Appeal: Conceptualization and Empirical Validation. Journal of the Academy of Marketing Science, 39, pp.392-406.

Fornell, C. and Larcker, D. (1981). Evaluating Structural Equation Models with Unobservable Variables and Measurement Error. Journal of Marketing Research, 18(1), pp.39-50.

Geuens, M., Weijters, B. and De Wulf, K. (2007). A New Measure of Brand Personality. International Journal of Research in Marketing, 26, pp.97-107.

Hair J., Black, W., Babin, B. and Anderson, R. (2010). Multivariate data analysis. Upper Saddle River, NJ, USA: PrenticeHall, Inc.

Hatcher, L. (1994). A step-by-step approach to using the SAS system for factor analysis and structural equation modeling. Cary, NC: SAS Institute.

Hooper, D., Coughlan, J. and Mullen, M. (2008). Structural Equation Modelling: Guidelines for Determining Model Fit. Electronic Journal of Business Research Methods, 6(1), pp.53-60.

Jöreskog, K. (1969). A General Approach to Confirmatory Maximum Likelihood Factor Analysis. Psychometrika, 34, pp.183-202.

Kaplan, M., Yurt, O., Guneri, B. and Kurtulus, K. (2010). Branding Places: Applying Brand Personality Concept to Cities. European Journal of Marketing, 44(9/10), pp.1286-1304.

Kim, K. (2000). Examination of Brand Personality and Brand Attitude within the Apparel Product Category. Journal of Fashion and Marketing Management, 4(3), pp.223-242.

Kim, C., Han, D. and Park, S. (2001). The Effect of Brand Personality and Brand Identification on Brand Loyalty: Applying Theory of Social Identification. Japanese Psychological Research, 43, pp.195-206.

Keller, K. (1993). Conceptualizing, Measuring, and Managing Customer-Based Brand Equity. Journal of Marketing, 57(1).

Kenya National Bureau of Statistics (KNBS) (2018). Integrated Household Budget Survey (KIHBS) for 2018. Nairobi: Kenya National Bureau of Statistics (KNBS).

Kim, J., Tae, H. and Martin, H. (2010). Dimensions of News Media Brand Personality. Journalism and Mass Communication Quarterly, 87(1), pp.117-134.

Kleine, R., Kleine, S. and Kernan, K. (1993). Mundane Consumption and the Self: A Social-Identity Perspective. Journal of Consumer Psychology, 2(3), pp.209-235.

Malhotra, N. (1988). Self-Concept and Product Choice: An Integrated Perspective. Journal of Economic Psychology, 9, pp.1-28.

Müller, B. and Chandon, J. (2003). The Impact of a Brand Website on Brand Personality. Electronic Markets, 13(3), pp.210-221.

Mohtar, M., Taha, A., Mutum, D. and Ghazali, E. (2013). Brand Personality Dimensions and Traits in Malaysia. In: Academy of Marketing Conference. Cardiff: Marketing Relevance.

MacCallum, R., Browne, M. and Sugawara, H. (1996). Power Analysis and Determination of Sample Size for Covariance Structure Modeling. Psychological Methods, 1, pp.130-149.

Murhpy, L. (2016). Destination Brand Personality - Testing the Applicability of Aaker's Brand Personality Dimensions to Tourism Destinations Using Confirmatory Factor Analysis. Travel and Tourism Research Association: Advancing Tourism Research Globally, 3.

Nunnally, J. (1978). Psychometric theory. 2nd ed. New York: McGraw-Hill.

Plummer J. (1984). How Personality makes a Difference. Journal of Advertising Research, 24, pp.27-31.

Ratnesh, K. and Kansal, A. (2017). An Empirical Study of Brand Personalities of Indian Telecommunication Service Providers. EduSys International Journal of Management Research, 1(1).

Roosta, A. and Madani, F. (2011). Impact of Service Quality and Consumer Decision Making on Brand Equity. Vision of Business Management, 1(1).

Supphellen, M. and Grønhaug, K. (2003). Building Foreign Brand Personalities in Russia: The Moderating Effect of Consumer Ethnocentrism. International Journal of Advertising, 22(2), pp.203-226.

Sweeney, J. and Brandon, C. (2006). Brand Personality: Exploring the Potential to Move from Factor Analytical to Circumplex Models. Psychology and Marketing, 23(8), pp.639-663.

Siguaw, J., Mattila, A. and Austin, J. (1999). The Brand Personality Scale-An Application for Restaurants. Cornell Hotel and Restaurant Administration Quarterly, 40(3), pp.48-55.

Tong, X., Su, J. and Xu, Y. (2018). Brand Personality and its Impact on Brand Trust and Brand Commitment: An Empirical Study of Luxury Fashion Brands. International Journal of Fashion Design, Technology and Education, 11(2), pp.196-209.

Tabachnick, B. and Fidell, L. S. (2007). Using multivariate statistics. 5th ed. Upper Saddle River, NJ: Pearson Allyn \& Bacon. 
Terason, S. (2012). An Empirical Evaluation of the Latent Structure of Brand Personality in Sport. NIDA Development Journal, Volume 52 Number 2

Thurstone, L. (1947). Multiple factor analysis: A development and expansion of vectors of the mind. Chicago: University of Chicago.

Thomas, B. and Sekar, P. (2008). Measurement and Validity of Jennifer Aaker's Brand Personality Scale for Colgate Brand. Vikalpa, 33(3), pp.49-61.

Valette-Florence, R. and De Barnier, V. (2013). Towards a Micro Conception of Brand Personality: An Application for Print Media Brands in a French Context. Journal of Business Research, 66(7), pp.97-903.

Xu, A., Liu, H., Gou, L., Akkiraju, R., Mahmud, J., Sinha, V., Hu, Y. and Qiao, M. (2016). Predicting Perceived Brand Personality with Social Media. In: Proceedings of the Tenth International AAAI Conference on Web and Social Media (ICWSM 2016). 